
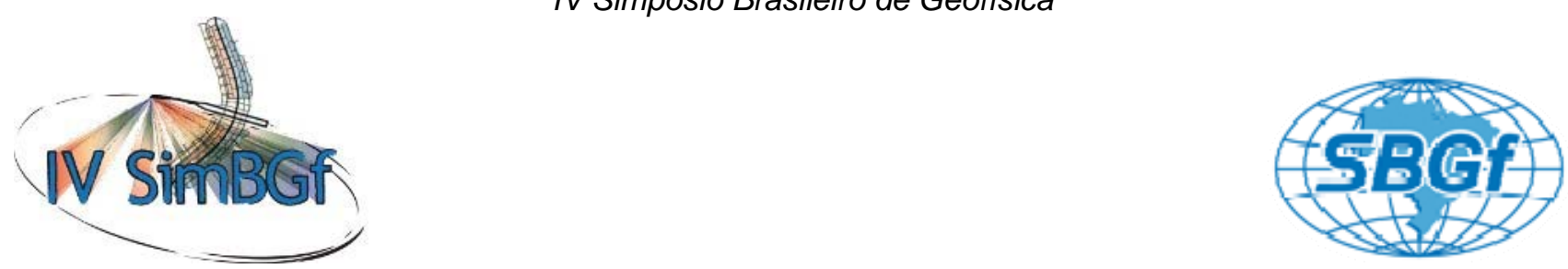

\title{
Levantamentos Geofísicos de Eletrorresistividade: uma contribuição ao estudo da caracterização geológica em uma área a sudoeste de Caçapava do Sul (RS)
}

Kleyzzer Rosso Rangel ${ }^{*}$, UNPAMPA, Brasil

Jobson de Oliveira, UNPAMPA, Brasil

Mario Jesus Tomas Rosales, UNIPAMPA, Brasil

Copyright 2010, SBGf - Sociedade Brasileira de Geofísica

Este texto foi preparado para a apresentação no IV Simpósio Brasileiro de Geofísica Brasília, 14 a 17 de novembro de 2010. Seu conteúdo foi revisado pelo Comite Técnico do IV SimBGf, mas não necessariamente representa a opinião da SBGf ou de seus associados. É proibida a reprodução total ou parcial deste material para propósitos comerciais sem prévia autorização da SBGf.

\section{Abstract}

The study area is located approximately $3 \mathrm{~km}$ southwest of the city of Caçapava do Sul, geographically bounded by latitudes $-53.5201--53.5148 \mathrm{~S}$ and longitudes $30.5432--30.5398 \mathrm{~W}$.

Geologically falls on the westernmost edge of the granite suite Caçapava South ( $\approx 540 \pm 11 \mathrm{Ma}$ ), composed of a geological context and syenogranites monzogranites. The work aimed at the achievement of a geophysical resistivity in detailed scale covering a grid of points of measurements of $30 \times 5$ meters for electrical profiling technique and execution of two surveys distributed spatially vertical electrical surface according to the NWSE with the objective of contributing to the characterization of sub-surface geology of the study area.

\section{Introdução}

A região de Caçapava do Sul, onde se insere a área de estudo, localiza-se na unidade geotectônica denominada Escudo Sul-rio-grandense situada na porção meridional da Província Mantiqueira (Almeida et al., 1977). Esta área registra os eventos relacionados ao Ciclo Brasiliano/PanAfricano (Porada, 1979) no sudeste da América do Sul.

A área de estudo se localiza na zona rural aproximadamente $3 \mathrm{~km}$ a sudoeste da cidade de Caçapava do Sul no estado do Rio Grande do Sul (RS), ocupando em superfície 0,62 $\mathrm{km}^{2}$ e delimitada geograficamente pelas latitudes $-53.5201--53.5148 \mathrm{~S}$ e longitudes -30.5432 - -30.5398 W (Figura 1).

Geologicamente se localiza no Complexo Granítico Caçapava do Sul (CGCS) composto principalmente por granodioritos, monzogranitos e sienogranitos (Nardi \& Bitencourt, 1989) e possui idade magmática em torno de $550 \mathrm{Ma}$ (Sartori \& Kawashita, 1985; Leite et al., 1995). As estruturas de deformação planar e lineares dessa unidade revelam atuação de zonas de cisalhamento transcorrentes durante a geração destas rochas.
O trabalho visou à realização de um levantamento geofísico de eletrorresistividade em escala de detalhe cobrindo uma malha de pontos de medições de $30 \times 5$ metros para a técnica de Caminhamento elétrico e a execução de duas Sondagens elétricas verticais distribuídas espacialmente em superfície segundo a direção NW - SE, com o objetivo de contribuir para a caracterização geológica em sub-superficie da área de estudo, em termos de mapear as ocorrências de fraturas no granito e inferir a sua continuidade em profundidade, delinear espacialmente em profundidade o contato do topo do granito (rocha sã) e inferir a profundidade do nível freático na área de estudo e a provável direção do fluxo das águas subterrâneas.

Os dados de eletrorresistividade de Caminhamento elétrico e de Sondagem elétrica vertical serão interpretados qualitativamente seguindo uma metodologia convencional e quantitativamente mediante técnicas de inversão.

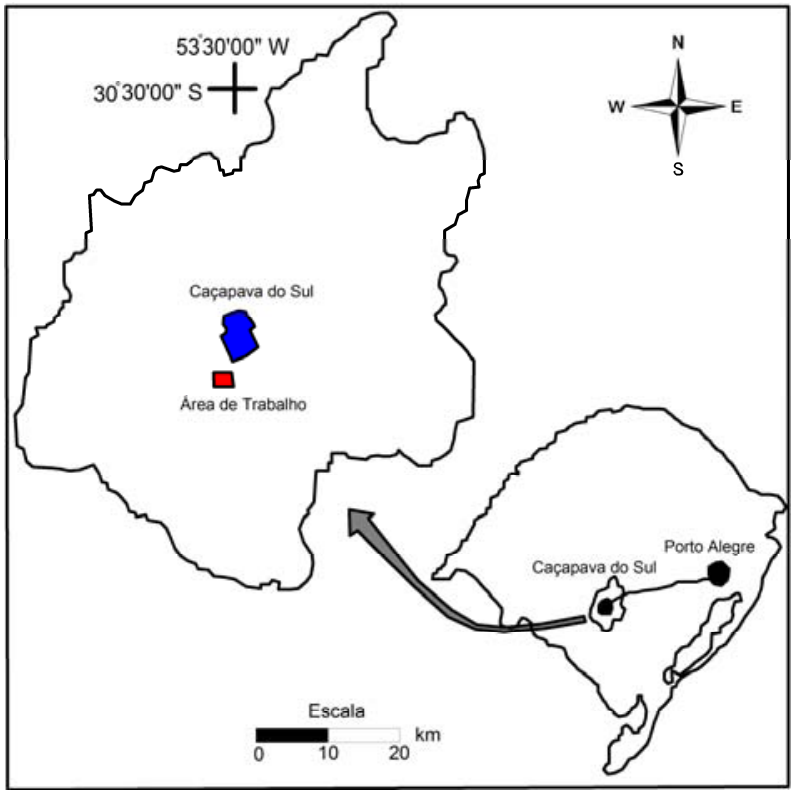

Figura 1 - Mapa ilustrativo de localização da área de estudo a sudoeste de Caçapava do Sul. 


\section{Arcabouço geológico da área de estudo.}

Conforme pode observar-se no mapa geológico da Figura 2, a área de estudo encontra-se em um contexto geológico regional limitado a oeste por uma faixa com disposição espacial norte-sul da Sequência metamórfica Vacacaí $(\approx 550 \mathrm{Ma})$, constituída por metapelitos, xistos quartzo-feldspáticos, quartzitos e rochas metavulcânicas, apresentando nos primeiros horizontes do solo uma cobertura formada por um manto de alteração de cor avermelhada com presença de material orgânico.

As altitudes topográficas caracterizam um relevo suavemente ondulado com variações de 430 a 418 metros na direção norte. O marco tectônico mostra a área inserida num contexto regional caracterizado pela presença de falhas com transcorrência sinistral seguindo um trend na direção NW-SE, alguns afloramentos de granito na área, mostram evidencias de um alto grau de alteração e a presença de rochas fraturadas.

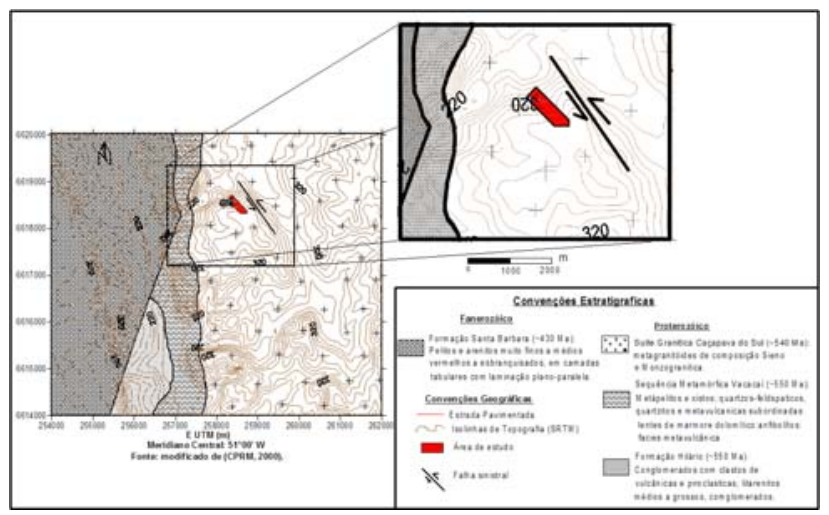

Figura 2 - Mapa geológico regional mostrando a área de estudo (adaptado de CPRM, 2000) e dados topográficos do SRTM (Shuttle Radar Topography Mission, USGS/NASA, 2007).

\section{Levantamento de eletrorresistividade.}

Para efetuar as medições referentes à aquisição de dados de eletrorresistividade, foi utilizado um Eletrorresistivímetro analógico de fabricação nacional de marca TECTROL.

Este equipamento se divide em dois módulos: o modulo transmissor que envia corrente continua até $500 \mathrm{~mA}$, e o modulo denominado receptor que mede a diferencia de potencial entre os eletrodos de medição em miliVolts $(\mathrm{mV})$.

\section{Caminhamento Elétrico (CE)}

As medições de CE foram realizadas utilizando o arranjo dipolo-dipolo com espaçamento entre os eletrodos de 5 metros. O espaçamento de 5 metros foi utilizado em 4 linhas com 120 metros de comprimento, conforme uma malha regular com uma separação entre linhas de 30 metros e distância entre pontos 5 metros (dipolo $=5$ metros), segundo a direção NE - SW, com a finalidade de obter um conhecimento detalhado da área segundo a extensão lateral e em diferentes profundidades, através de mapas de resistividade aparente a diferentes níveis de profundidade teórica.

O mapa da Figura 3 mostra a malha de aquisição de dados de CE e o posicionamento das SEVs na área de estudo, assim como a presença de algumas feições fisiográficas presentes na superfície do relevo topográfico.

\section{Sondagem Elétrica Vertical (SEV)}

No caso particular da técnica de SEV com o arranjo Schlumberger (Orellana, 1982), foi utilizada uma disposição de maneira que os eletrodos ( $A B, M N)$ permanecessem simetricamente com relação ao centro do arranjo, tornando este ponto como referencia para a leitura dos dados. Foram realizadas duas Sondagens elétricas verticais distribuídas espacialmente em superfície segundo a direção NW - SE, com uma abertura máxima entre os eletrodos de corrente $(A B / 2)$ de 100 metros.

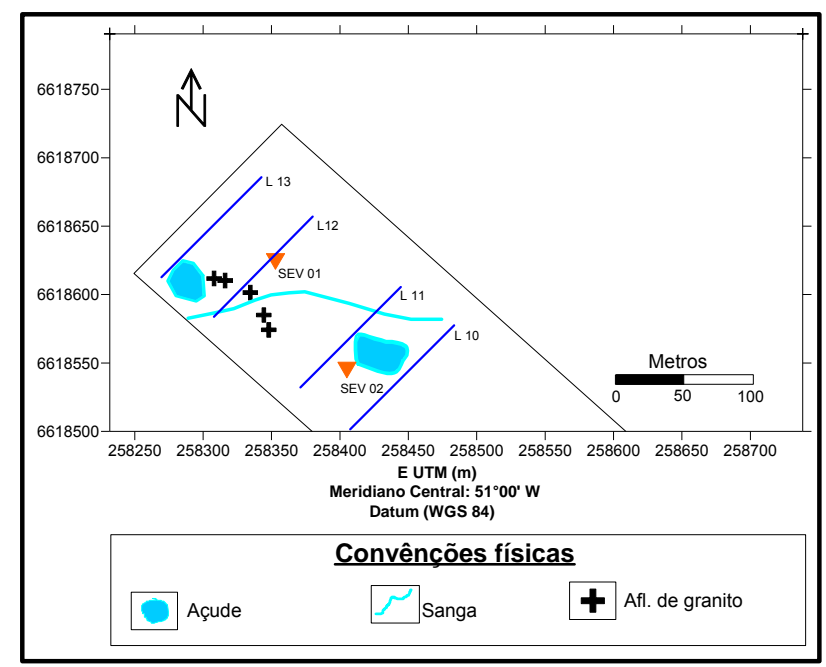

Figura 3 - Mapa esquemático mostrando a malha de aquisição de dados de CE e o posicionamento das SEVs.

\section{Interpretação dos dados de Caminhamento Elétrico}

Os mapas de resistividade aparente apresentados mostram os resultados obtidos ao longo das linhas de CE na área de estudo, para os níveis de profundidade teórica 10, 15 e 20 metros (Figuras 4, 5 e 6). A interpretação dos mapas a diferentes profundidades assume um caráter qualitativo ao tentar inferir setores anômalos de altos e baixos de resistividade elétrica aparente, e correlacionar eles, com uma provável continuidade em profundidade, associados aos diferentes litotipos presentes na área.

No mapa da Figura 4 (isovalores de resistividade aparente a $10 \mathrm{~m}$ de profundidade), observa-se na porção norte a presença de uma feição resistiva com valores em 
torno de 170 - 200 Ohm.m, associado a presença de solo com fragmentos grossos de rocha fraturada (granito) o que é possível corroborar no mapa da Figura 3. Destacase na porção central seguindo um eixo ao longo da área na direção NW-SE a presença de uma estreita faixa com valores baixos de resistividade $(40$ - 50 Ohm.m) associada muito provavelmente a presença de fraturas no granito que poderiam eventualmente estar preenchidas com um material mais condutivo que poderia tratar-se de argila ou eventualmente a presença de percolação de água.

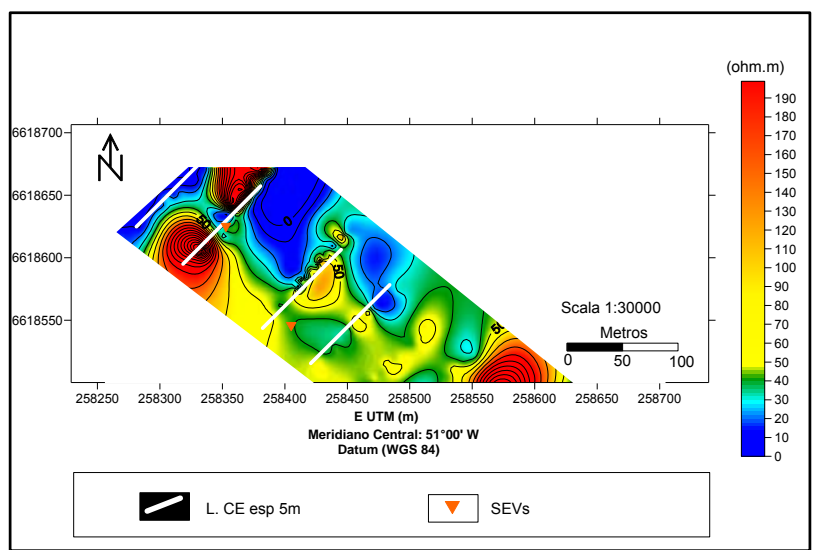

Figura 4 - Mapa de contorno de resistividade aparente a $10 \mathrm{~m}$ de profundidade. Intervalo de contorno: 10 Ohm.m.

No mapa da Figura 5 (isovalores de resistividade aparente a $15 \mathrm{~m}$ de profundidade), observa-se na porção norte da área a presença de um alto resistivo com valores em torno de $650 \mathrm{Ohm} . \mathrm{m}$, associado a presença do granito que aflora em alguns pontos da área e conforme critérios interpretativos poderia apresentar continuidade em profundidade. Destaca-se na porção central a presença de um eixo com valores baixos de resistividade $(150 \quad-180 \quad$ Ohm.m $)$ associado provavelmente a presença de fraturas no granito que poderiam eventualmente estar preenchidas com um material mais condutivo que poderia tratar-se de argila ou eventualmente a presença de percolação de água.

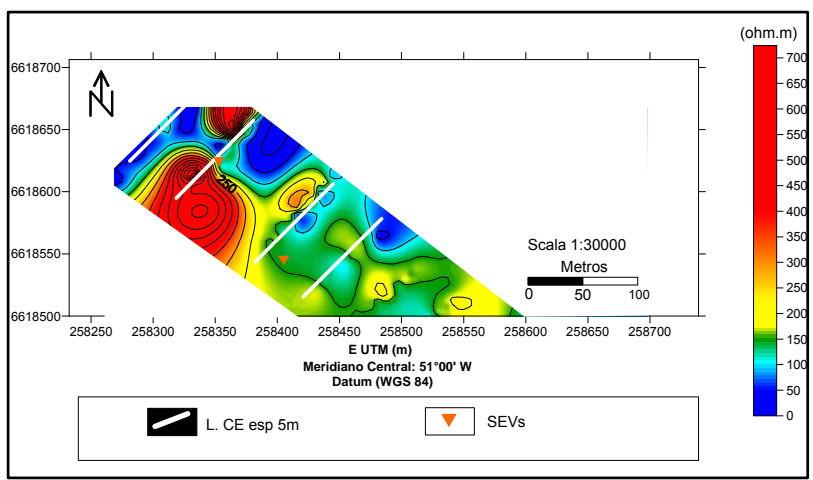

FIGURA 5 - Mapa de contorno resistividade aparente a $15 \mathrm{~m}$ de profundidade, intervalo de contorno 50 Ohm.m.

No mapa de resistividade aparente a profundidade de 20 metros (Figura 6) destaca-se como característica comum aos outros mapas de profundidades teóricas (Figuras 4 e 5), uma feição na porção central caracterizando um eixo com valores baixos de resistividade (250 - 350 Ohm.m) associado provavelmente a presença de fraturas no granito.

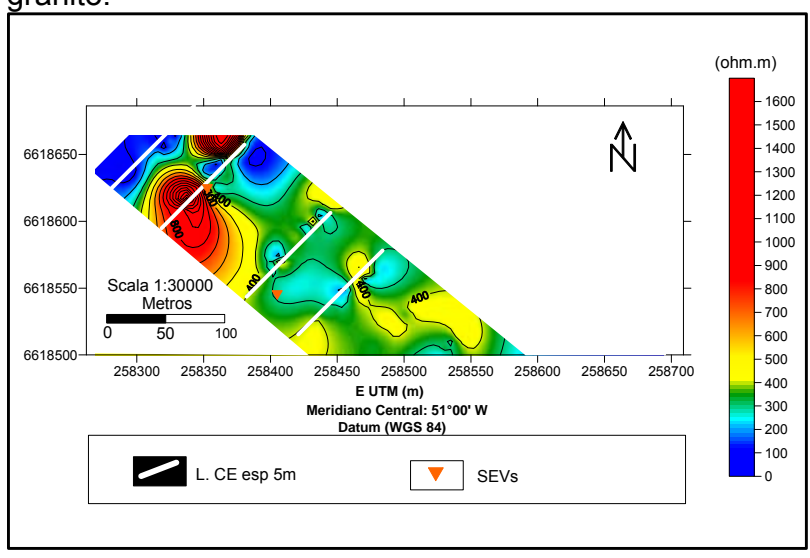

Figura 6 - Mapa de contorno de resistividade aparente a $20 \mathrm{~m}$ de profundidade. Intervalo de contorno: 100 Ohm.m.

É possível ressaltar a partir dos resultados da interpretação dos três mapas de contorno de resistividade aparente as profundidades de 10,15 e 20 metros (Figuras 4, 5 e 6) a presença de uma zona de fratura que apresenta continuidade em profundidade e se alonga na direção NW-SE da área, essa zona de fratura seria um canal propicio para a circulação de águas subterrâneas na área, o que poderia correlacionar-se com a presença de um eixo com valores baixos de resistividade.

\section{Interpretação das curvas de SEVs.}

Para calcular a distribuição de resistividade elétrica no subsolo se utilizam programas de inversão dos dados de resistividade elétrica, no caso particular da SEV, as curvas de resistividade obtidas em campo, em função da distância $A B / 2$, se ajustam mediante um algoritmo matemático visando encontrar um modelo de camadas de resistividade elétrica em função da profundidade (1D), cuja resposta de resistividade aparente seja compatível com os dados observados no campo.

Foi utilizado para a inversão dos dados das SEVs o programa IPI2Win Version 3.0.1a. elaborado pela Universidade de Moscou, 2003.

A Figura 7 e a Figura 8 mostram os modelos gerados através do processo de inversão das SEVs realizadas na área de estudo (SEV 1 e SEV 2).

As curvas de SEVs com dados observados no campo foram classificadas de acordo com a seqüencia das camadas elétricas compatíveis com cortes geológicos que afloram nas proximidades da área de estudo. 


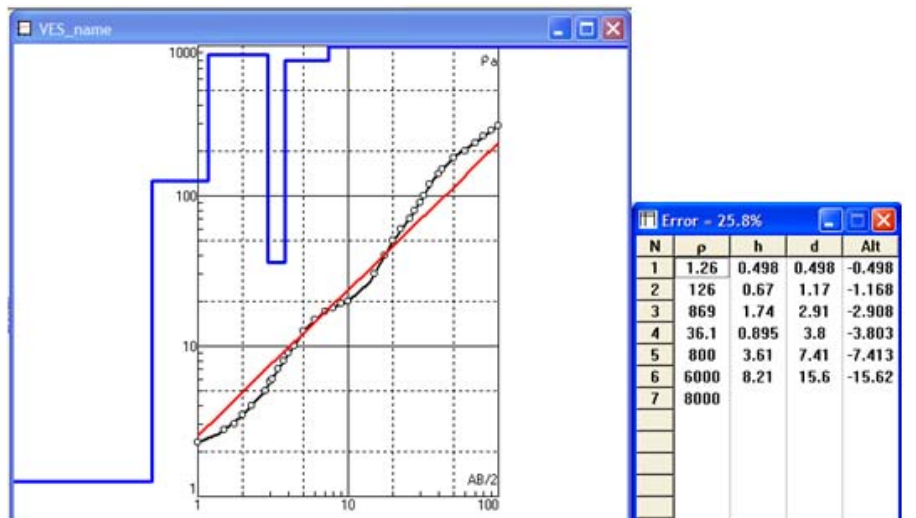

Figura 7 - Modelo de inversão para SEV 1 (IPI2Win, 2003).

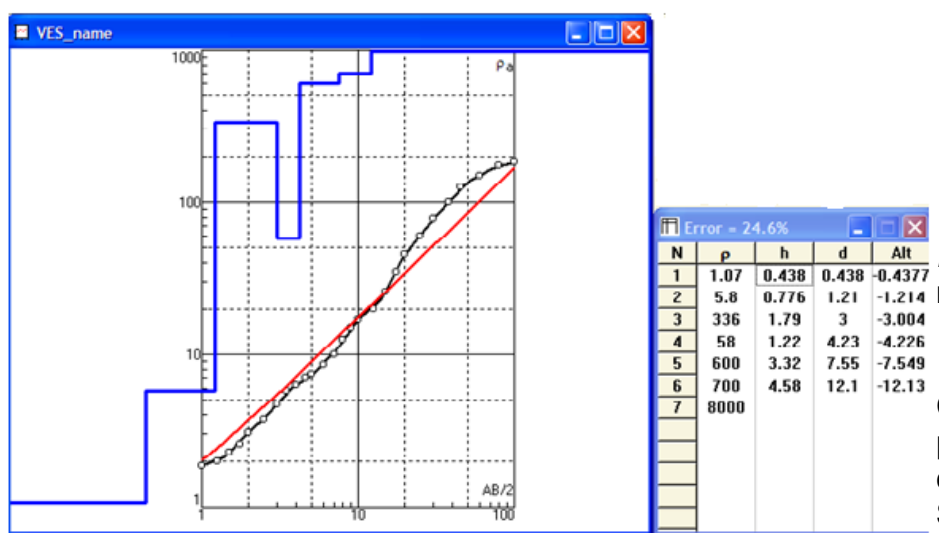

Figura 8 - Modelo de inversão para SEV 2 (IPI2Win, 2003).

Para as curvas de SEVs os modelos básicos iniciais obtidos conforme o processo de inversão utilizando (Bobachev A. et al 2003), baseiam-se de maneira geral em curvas de seis camadas do tipo AKHA.

\section{Descrição da seção geológica - geofísica baseada na interpretação dos modelos obtidos para as SEVs.}

Nas Figuras 9 e 10, pode observar-se os resultados obtidos ao longo da seção geológica - geofísica baseada na interpretação dos modelos obtidos para a SEV 1 e SEV 2, a presença de pacotes de espessuras diferentes caracterizados por diferentes litologias e diferentes patamares de valores de resistividade.

A interpretação ao longo da seção que correlaciona às duas Sondagens elétricas verticais (SEV 1, SEV 2) na direção NW-SE, corresponde espacialmente com a porção norte da área de estudo, caracterizada por os valores mais baixos das cotas topográficas em torno de 418 metros.

Observa-se a presença de um pacote superior com uma espessura aproximada de 1,2 metros e valores baixos de resistividade (6 - 120 Ohm.m) associado a um manto de alteração composto por um solo úmido com material orgânico.

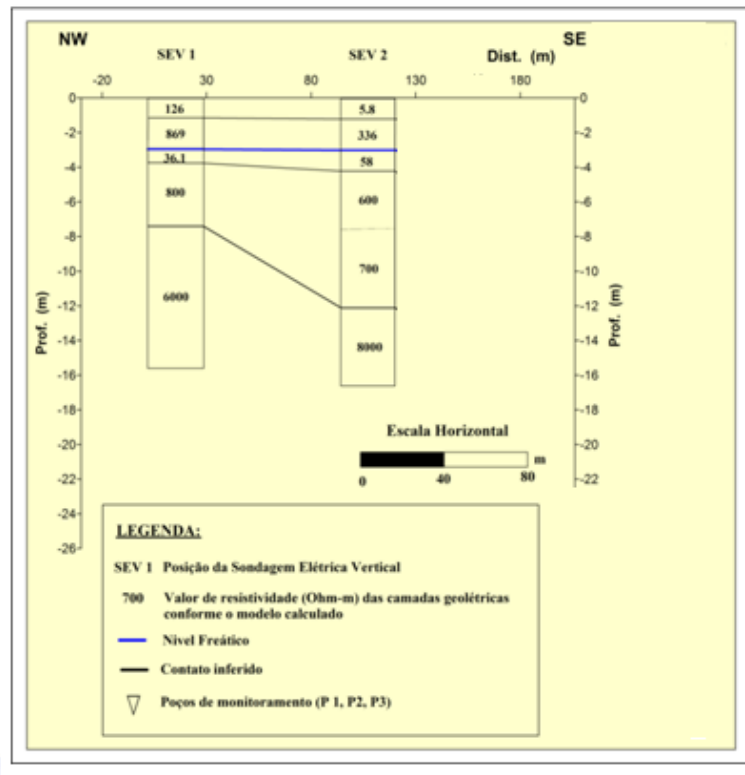

Figura 9 - Seção geofísica baseada na interpretação dos modelos obtidos para a SEV 1 e SEV 2.

Correlacionando as duas colunas geoelétricas obtidas produto da SEV 1 e SEV 2 podemos observar uma continuidade lateral na direção noroeste-sudeste (NW$\mathrm{SE})$ da área de estudo, do nível freático inferido aproximadamente a uma profundidade de 3 metros.

Um fato interpretativo a ser ressaltado é que a presença de água (nível freático inferido) conforme a interpretação da SEV 1 e SEV 2, estaria associada provavelmente a presença de fraturas existentes no granito.

Aproximadamente a partir dos 4 metros de profundidade observa-se a presença de um granito fraturado com alto grau de umidade apresentando valores de resistividade em torno de 600 a 800 Ohm.m.

Segundo critérios interpretativos é possível inferir na área de estudo a presença do contato do topo do granito, sem

alterações, o que denominamos de rocha sã, a uma profundidade aproximada de 7,5 metros, apresentando valores em torno de 6000 Ohm.m. 


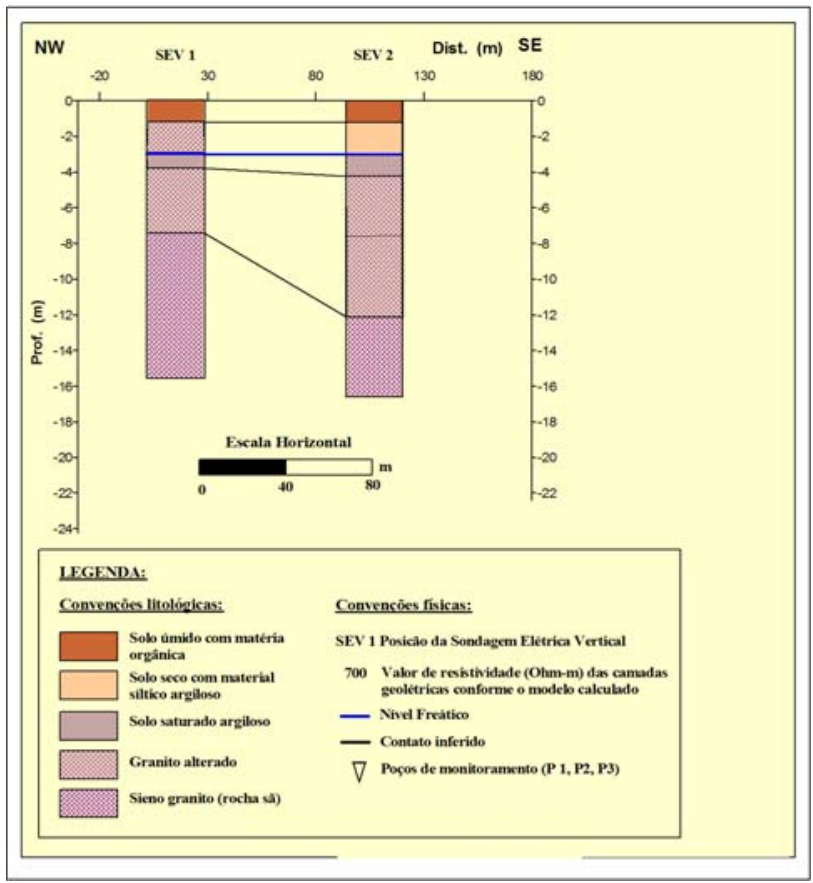

Figura 10 - Seção geológica - geofísica baseada na interpretação dos modelos obtidos para a SEV 1 e SEV 2.

\section{Conclusões}

Os resultados obtidos no trabalho se mostram consistentes do ponto de vista de interpretação geológico - geofísica conjunta de maneira integrada dos dados geofísicos oriundos dos levantamentos de eletrorresistividade com as técnicas de Caminhamento Elétrico e de Sondagem Elétrica Vertical.

Aportou parâmetros geométricos referentes à extensão lateral e em profundidade dos primeiros horizontes do solo, em termos de estabelecer e delinear possíveis contatos entre o granito sem alteração (rocha sã) e a rocha alterada (solo intemperizado).

Caracterização geofísica e identificação espacial em profundidade da presença de fraturas no granito e seu inferimento de continuidade até níveis superiores próximos da superfície.

Delineamento espacialmente em profundidade do contato do topo do granito (rocha sã).

Inferimento da profundidade do nível freático na área de estudo e a provável direção do fluxo das águas subterrâneas.

A metodologia utilizada no processamento dos dados geofísicos combina a interpretação qualitativa e quantitativa mediante a aplicação de processos de inversão para a obtenção de modelos geofísicos que possam ser correlacionáveis com a interpretação geológica.
Confecção de modelo geofísico geológico baseado na interpretação dos dados geoelétricos de sondagem elétrico vertical.

Os resultados obtidos no trabalho foram satisfatórios e constituem resultados pioneiros para a área de estudo.

Recomenda-se para futuros trabalhos geofísicos de esta natureza na região de estudo, a continuidade de execução de levantamentos geofísicos em escala de detalhe visando a utilização de novas técnicas de exploração geofísica e a posterior integração e interpretação desses dados.

\section{Agradecimentos}

Nossos agradecimentos a UNIPAMPA pela disponibilidade dos equipamentos na execução dos trabalhos de campo e ao grupo de colegas que nos ajudaram nas medições.

Agradecemos de maneira pessoal ao Prof. Dr. Mario Jesus Tomas Rosales pela orientação do trabalho.

\section{Referências}

ALMEIDA, F. F. M.; Hasui, Y.; Brito Neves, B. B. \& FUCK, R. A. Províncias Estruturais Brasileiras. In: SIMPÓSIO DE GEOLOGIA DO NORDESTE, 8., Campina Grande, Atas..., SBG, p. 363-391, 1977.

BOBACHEV A; I MODIN; V. SHEVNIN. 2003 IPI2Win software. Versión 3.0.1a. Geoscan-M Ltd. Moscow State University. Russia.

CPRM - SERVIÇO GEOLÓGICO DO BRASIL. (2000). Programa Levantamentos Básicos do Brasil - Carta Geológica Folha Cachoeira do Sul SH22-Y-A.

Nardi, L. V. S. \& Bitencourt, M. F. A. S. 1989. Geologia, petrologia e geoquímica do Complexo Granítico de Caçapava do Sul, RS. Revista Brasileira de Geociências, 19: 153-169.

ORELLANA, E. 1982. Prospección geolétrica en corriente continua. Paraninfo, Madrid, 1-578.

PORADA, H. 1979. The Damara-Ribeira Orogen of the Pan African-Brasiliano Cycle in Namibia (Southwest Africa) and Brazil as interpreted in terms of continental collision. Tectonophysics, 57: 237-265, 1979.

SARTORI, P. L. P. \& KAWASHITA, K. Petrologia e geocronologia do Batólito granítico de Caçapava do Sul, 
RS. In: SIMPÓSIO SULBRASILEIRO DE GEOLOGIA, 2., Florianópolis, 1985, Atas...,SBG, p. 102-115, 1985.

TECTROL - Equipamentos elétrico eletrônicos LTDA.

USGS/NASA, 2007. SRTM (Shuttle Radar Topography Mission) Digital Elevation Model, disponível em (www2.jpl.nasa.gov/srtm/); 